\title{
Linking the Continental Environmental Quaternary History of Southern Africa with Ocean Currents and Antarctica
}

\author{
Cape Town, South Africa, 15-17 May 2002
}

The main goals of this 3 day workshop were to identify the crucial gaps in understanding of ocean-continental climate links for southern Africa and the surrounding oceans, as well as to actively promote broader cooperation across disciplinary and international boundaries. The workshop was held to allow scientists from Europe to meet with colleagues and students from South African institutions, to discuss the scientific issues, to promote research efforts, and to encourage co-operation with the industries exploring natural resources along the South African margins. Participants were drawn from a broad spectrum of disciplines including oceanography, archaeology, geology, geography, palaeoclimatology, and botany.

An emerging focus in global palaeoclimate research is the nature of the links between ocean circulation and continental climate. This is an area of particular interest in southern Africa as it is strongly influenced by oceanic conditions. Connections between the Benguela upwelling system, the winter rainfall/summer drought climate, and the unique Fynbos flora of the West coast, as well as the warm Agulhas current and summer rainfall climate/savanna woodlands of the eastern and interior regions of southern Africa are apparent today. But we know little about how these links varied in the past, or indeed about variation of water masses in the tropical Indian, southern subantarctic and polar oceans. Such information is important because of the key role these oceans play in energy transport within the southern hemisphere and between hemispheres.

Day 1 began with a brief introduction on the chief elements of modern oceanographic conditions around southern Africa, followed by reviews of ongoing marine sediment work off the West coast. Closer to shore, the Orange River mudbelt (HODSA project) and the DeBeers exploration and palaeoenvironmental research were described. An overview of ongoing monitoring of the modern Benguela ecosystem completed the West coast session. Thereafter, attention turned to the modern and palaeo Agulhas Current system, and its teleconnection to climate change in Antarctica and the North Atlantic.

Discussions during day 2 centered around continental conditions and climatic links between ocean and continent. Topics included longterm fluctuations in summer season rainfall from the Tswaing crater sediment record, Kalahari dune mobility, stalagmite records, possible links to Antarctic circulation, vegetation histories and dust transport recorded in marine sediment cores. A provocative presentation on long-term floral evolution emphasized the roles of fire and atmospheric $\mathrm{CO}_{2}$ levels. Agreement emerged among several studies that there was a northward shift of the winter rainfall belt along the west coast under full glacial conditions. Archaeological and palaeontological evidence was used to examine direct links between marine conditions and those of the adjacent West coast in the Holocene and late Pleistocene. The final sessions revolved around emerging opportunities for new joint research projects over the next 2 to 3 years that are likely to evolve due to scheduled expeditions with British, French, German and Spanish research vessels. One project will target extraction of a series of high resolution marine records from nearshore sites along the West coast, with clear links to coastal environments. Two complementary investigations will target transport of Agulhas waters and eddies, one focused on the retroflection area and the other on the SW Indian Ocean.

Day 3 was dedicated to the discussion of combining efforts within the framework of the different projects, and ways to strengthen international collaboration. It was agreed that the nature of ocean-continent connections effecting variability and history of marine systems and continental environments (Fig. 1) should

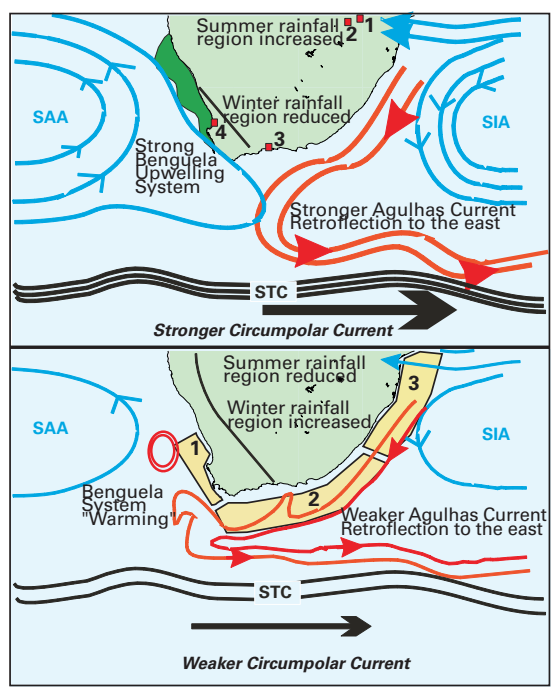

Fig. 1: Schematic view of atmospheric and oceanic processes driving South African precipitation patterns (Adapted from Cohen and Tyson 1995, and the ECRAN project UBordeaux). SAA and SIA are atmospheric South Atlantic and South Indian ocean Anticyclones, STC is Subtropical Convergence Zone. The red squares in the upper panel denote examples for land climate archives 11: Cold Air Cave, 2: Tswaing crater, 3: Nelson Bay Cave, 4: Steenbokfontein/ Elands Bay Cave), while yellow boxes in the lower panel outline the areas of marine coring programmes anticipated in the next 2 years 11: West coast margin, 2: Agulhas passage, 3: Limpopo/Sambesi Fans).

be the major objective in the future, and that these should be considered within the broader context of Antarctic and North Atlantic changes. The workshop also concluded that a science plan following the workshop theme should be developed immediately. This should help to create a coherent international research strategy and encourage support by potential partners from industries, funding agencies and political institutions.

We thank the workshop participants for their contributions and the National Research Foundation of South Africa and PAGES for financial sponsorship of the workshop.

\section{JULIA LEE-THORP}

University of Cape Town, South Africa; jlt@beattie.uct.ac.za

\section{RALPH SchNeideR}

Bremen University, Germany; rschneid@uni-bremen.de 